\title{
Are you looking at your channel cleaning brush?
}

\author{
Ahmed Gado ${ }^{1}$, Basel Ebeid ${ }^{2}$ \\ ${ }^{1}$ Department of Medicine, Bolak Eldakror Hospital, Giza, Egypt \\ ${ }^{2}$ Department of Tropical Medicine and Infectious Diseases, Banysweef University, Banysweef, Egypt
}

doi: 10.3396/ijic.V7i3.026.11

The risk of transmission of infection during gastrointestinal endoscopy is estimated at 1 case per 1.8 million procedures. ${ }^{1}$ Failure to follow established guidelines for reprocessing has resulted in the transmission of infectious agents causing serious patient injury and/or death. ${ }^{2}$ Ideally, endoscope reprocessing comprises two basic components, manual cleaning and automatic disinfection. Manual cleaning includes brushing and exposure of all external and accessible internal components to a low-foaming, enzymatic, endoscope-compatible detergent. ${ }^{3}$ To successfully disinfect endoscopes, all debris must first be removed. Whether using a reusable or single-use brush, a couple of considerations are imperative. ${ }^{4}$ The brush should be appropriate to the size of the channel being cleaned. Good condition of the brush (protective tip is not missing, bristles are not absent and the delivery tube is not kinked). The minimal number of times each lumen should be brushed should be identified as "until the brush comes out clean".
Bolak Eldakror Hospital is a secondary-care governmental hospital in Giza, Egypt. The gastrointestinal endoscopy unit was founded in 1999. We accidentally discovered absent bristles of the channel cleaning brush (Figure 1). Most probably the brush had been used for several weeks before the discovery of missing bristles leading to inadequate cleaning of endoscopes channels. The brush was replaced by a new one.

To ensure adequate cleaning and disinfection of the gastrointestinal endoscopes it is recommended that disposable brushes are used. If not available and cleaning brushes are reused then the end of the brush is observed and cleaned each time it emerges from the end of the endoscope before pulling it back through the channel and after each use. Appropriate staff training, protocols in place, auditing against the standard and microbiological tests of swabs taken from endoscopes for bacteriological monitoring are also recommended. ${ }^{5}$

\footnotetext{
Corresponding author

Ahmed Gado,

Bolak Eldakror Hospital, Giza, Egypt,

Email: agado1954@yahoo.com
} 


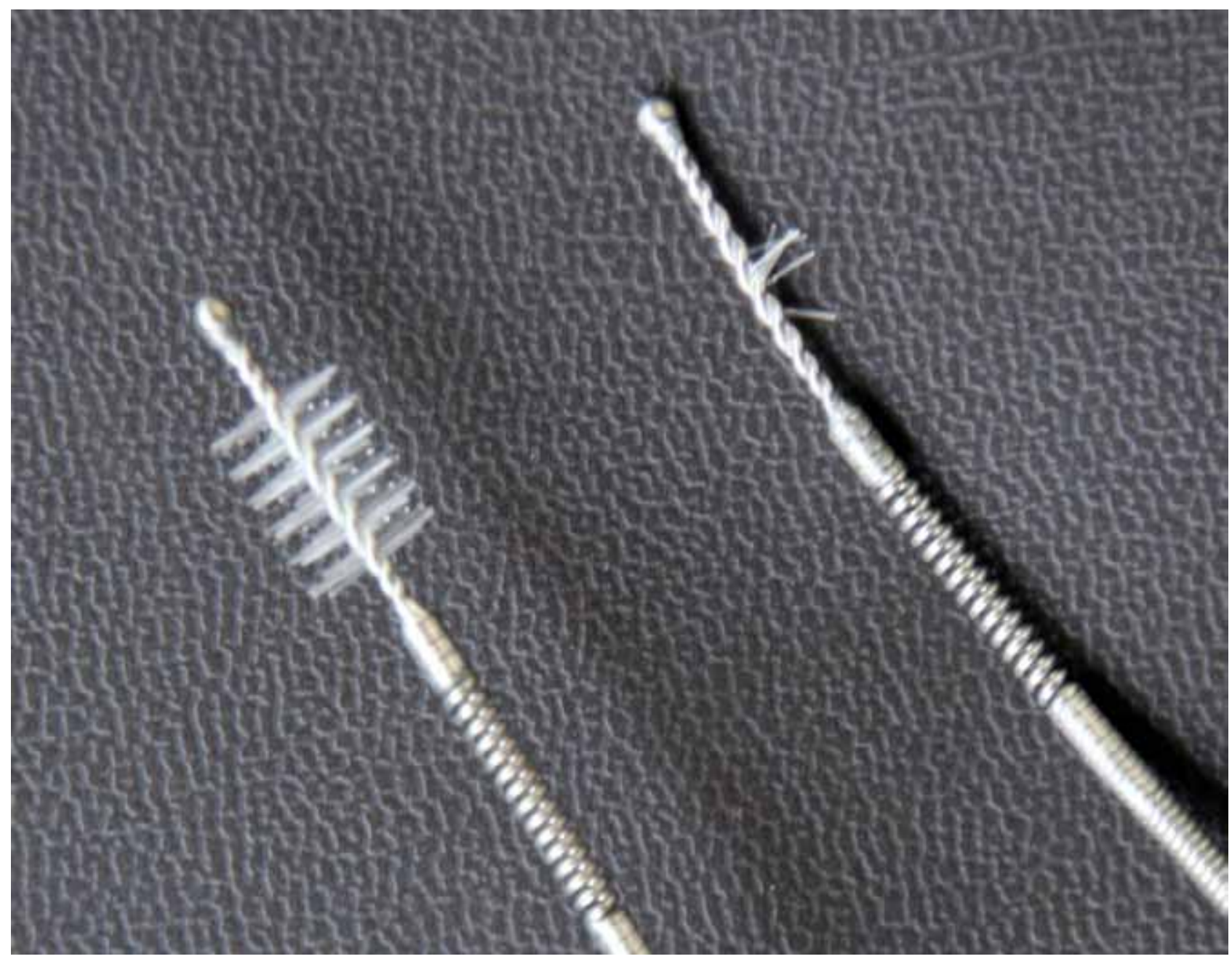

Figure 1: New brush (left) and old brush (right)

\section{References}

1. Banerjee S, Nelson DB, Dominitz JA, et al. Reprocessing failure. Gastrointest Endosc 2007; 66(5): 869-871. http. dx.doi.org/10.1016/j.gie.2007.06.019

2. Catalone B, Koos G. Reprocessing flexible endoscopes. June 2005. Available at: www.olympusamerica.com/msg_section/ files/mic0605p74.pdf
3. WGO-OMGE and OMED practice guideline: Endoscope Disinfection December 2005. Available at: www.omed. org/downloads/pdf/guidelines/wgo_omed_endoscope_ disinfection.pdf

4. Endoscope manual cleaning. Available at: www. educationaldimensions.com/eLearn/environment/ manualCleaning.php

5. Gado A, Ebeid B. Impact of a continuous quality improvement program on infection control of endoscopes. Int J Infect Control 2009, v5:i1 10.3 http.dx.doi.org/10.3396/ijic.V5i1.010.09 